\title{
OBSERVACIONES SOBRE LA CIENCIA DEL DERECHO
}

\author{
Antonio Bascuñán Rodríguez ${ }^{1}$
}

"El Derecho debe ser sabido de modo pensante; tiene que ser en sí mismo un sistema, y sólo como tal puede tener vigencia en las naciones cultas". (Hegel, Principios de la Filosofia del Derecho. $\$ 211$, Agregado).

1. El Consejo Editorial de la Revista Derecho y Humanidades me ha solicitado redactar algunas notas sobre el valor científico de la jurisprudencia, con el fin de realizar una discusión sobre este tópico entre Profesores de la Facultad.

Como medida preliminar, quisiera replantear el tema de la discusión. En vez de preguntarnos una vez más si la jurisprudencia es o no ciencia, creo preferible concentrar nuestros esfuerzos en esta ocasión en elucidar en qué sentido la dogmática jurídica contribuye de un modo específico a la racionalidad de la argumentación jurídica.

No es que estime que la pregunta general por el status metodológico de la labor intelectual de los juristas carezca de sentido. Ella presupone sin embargo respuestas simples a cuestiones que no lo son. La caracterización de la "ciencia" es una cuestión eminentemente controvertible, y bajo el común denominador de "jurisprudencia" son realizadas actividades argumentativas muy variadas. Además, en la medida en que con el término "ciencia" se designe algún tipo de actividad argumentativa institucionalizada, tal como está planteada, la pregunta adquiere un sesgo descriptivo, ya que se transforma en una comparación de actividades argumentativas. Este sesgo hace que el tema pierda su relevancia intrínseca y adquiera ya su mero planteamiento una impronta de arbitrariedad. ¿Por qué, en efecto, tendrá que asemejarse la jurisprudencia a la matemática o a la química?

La prioridad de la dogmática jurídica como objeto específico de análisis proviene, por otra parte, de nuestro trasfondo cultural. La comprensión universi-

\footnotetext{
'Profesor de Introducción al Derecho y Derecho Penal, Facultad de Derecho, Universidad de
} Chile. 
taria del Derecho que es característica de la tradición jurídica continental asigna a un cierto tipo de discurso acerca del Derecho un valor específico en orden a asegurar la racionalidad de la decisión jurisdiccional. Por eso es que aparece como especialmente relevante preguntarse en qué consiste (o debe consistir) la contribución específica de ese tipo de discurso, que se supone es el que desarrollan los juristas en su actividad universitaria. Si esa actividad es no "científica", en un sentido metodológico restringido, es algo que me parece menos importante.

Por cierto, el escéptico radical podría replicar, ¿y por qué habría de argumentar racionalmente el jurista? Yo no dispongo de una dúplica categórica que oponer a esta réplica. Parto simplemente de la base que la mediación del poder por el Derecho es valiosa, que esa mediación consiste en un control argumentativo del poder, obligado a justificar sus decisiones. Asumo, pues, que Derecho evidencia una pretensión de rectitud y que la dogmática jurídica manifiesta una pretensión de racionalidad correlativa. El propósito de esta nota es contribuir a señalar los aspectos que hemos de tomar en consideración para elucidar en qué consiste (o debe consistir) esta pretendida racionalidad ${ }^{2}$. El que quiera jugar a Nietzsche o a Foucault tiene toda mi comprensión, pero participa en otro juego.

2. Un primer punto es diferenciar las clases o tipos de discurso que pueden caer bajo el rótulo de "ciencia del Derecho".

Un tipo de discurso es el característico de la teoría general del Derecho, cuyas variantes más conspicuas son la de inspiración analítica y la de inspiración sociológica. La aspiración de la primeras es explicar el Derecho presuponiendo su identidad específica como objeto de análisis, y procediendo a través de una clarificación de los conceptos y categorías propios de los agentes del sistema jurídico. La aspiración de la segunda es explicar el derecho presuponiendo su

\footnotetext{
${ }^{2}$ Para la redacción de estas notas he tenido presente las siguientes obras: Niklas Luhmann, Sistema Juridico y Dogmática Juridica (1974), Madrid, 1983; Ralf Dreier, Zur Theoriebildung in der Jurisprudenz (1978), en del mismo, "Recht-Moral-Ideologie", Frankfurt del Meno, 1981, págs. 70 y ss.; Ulfrid Neuman, Wissenschaftstheorie der Rechtswissenschafts, en Arthur Kaufmann y Winfried Hassemer (eds.), Einführung in Rechtsphilosophie und Rechtstheorieder Gegenwart, $5^{\mathrm{a}}$ edición, Müchen 1989, págs. 375 y ss. (hay traducción al castellano de esta obra); Robert Alexy, Theorie der Juristischen Argumentation, $2^{\text {a }}$ edición, Frankfurt del Meno, 1991, especialmente su sección C-II-2.4 (hay traducción al castellano de esta obra); Claus Wilhelm Canaris, Función, Estructura y Falsación de Teorias Juridicas (1993), Madrid, 1995.
} 
interrelación con el sistema social general de la sociedad. A la primera pertenecen las obras de grandes juristas, como Austin, Kelsen y Hart. A la segunda, las obras de sociólogos eminentes, como Weber y Luhmann.

Otro tipo de discurso es el propio de la dogmática jurídica, diversificada en al menos tantas disciplinas específicas distintas como distintos ámbitos jurídicos específicos ("ramas del Derecho") reconoce la enseñanza universitaria del Derecho. El objetivo de la dogmática jurídica es el análisis y reconstrucción del Derecho vigente, con el propósito práctico de anticipar la solución correcta desde la perspectiva del Derecho vigente a cualquier caso de relevancia jurídica.

Cuál sea la relación que existe entre la teoría del Derecho y la dogmática juridica, eso es algo sumamente incierto, ya que depende en definitiva de la orientación metodológica que asuman una y otra. En principio es claro que la relevancia práctica de los resultados de la teoría general del Derecho depende de su relación con el uso efectivo de ciertos conceptos y categorías por parte de jueces y juristas, y que, por otra parte, estos se benefician de la clarificación conceptual llevada adelante por aquella. Sin embargo, muchas cuestiones centrales de la teoria juridica - el concepto procedimental de validez- son cuestiones asumidas como resueltas por la dogmática jurídica. Por otra parte, cuestiones centrales para la dogmática jurídica-las definiciones sustantivas de principios generales-tienen que ser consideradas como contingentes por la teoría general del derecho de inspiración analática o sociológica. Por ello, en general parece razonable admitir una relativa independencia y vigilancia recíproca entre ambas disciplinas, poniendo énfasis en sus diferencias.

3. Una primera diferencia entre uno y otro discurso se relaciona con la mayor generalidad o particularidad de sus aseveraciones.

En la medida que los enunciados dogmáticos son enunciados relacionados con algún orden jurídico vigente, la verosimilitud o corrección de dichos enunciados llega hasta donde alcanza al ámbito de validez de dicho sistema jurídico. Los enunciados de la teoría general del Derecho, en cambio, pretenden ser verosímiles para cualquier ámbito geográfico o étnico en que el orden social posea una determinada estructura, a la cual se refiere el concepto de Derecho. Es en este 
sentido que desde Hobbes se aduce que la teoría analática del Derecho es una teoría "general"3.

4. Una segunda, y más importante diferencia, es la que se relaciona con el status lógico de los enunciados de cada discurso.

La teoría general del Derecho pretende que sus enunciados son constatativos, aunque puedan tener una fisonomía característica (enunciados de comprensión) que los diferencia de los modelos paradigmáticos de enunciados constatativos (enunciados de explicación).

La dogmática jurídica formula enunciados de diversa naturaleza ${ }^{4}$. En algunos contextos de su análisis, enuncia aserciones constatativas, de la forma "es el caso que en la sociedad S se considera conforme al Derecho vigente que la acción X se encuentra prohibida/permitida/mandada". En otros contextos, la dogmática formula aserciones de naturaleza más bien normativa o práctica, de la forma: "en virtud de las razones A, B y C, en el caso X debe ser aplicable la norma $\mathrm{Y}$ ", o bien de la forma: "en virtud de las razones A, B y C, la disposición $\mathrm{Y}$ debe ser entendida como comprensiva de la norma Z". La dogmática jurídica se mueve a lo largo de todo el espectro de perspectivas en las que se puede situar un hombre interesado en conocer la solución jurídica correcta a un determinado problema práctico: desde la necesidad de la información más general y simple, susceptible de ser satisfecha mediante enunciados puramente constatativos, hasta la necesidad de la información más compleja, sólo susceptible de satisfacción mediante argumentos evaluativos, que anticipen la mejor justificación jurídica de una pretensión ante un tribunal.

5. Para expresar esta orientación a la praxis de la dogmática jurídica existe una buena fórmula terminológica, de uso frecuente: entre la argumentación de lege lata y la argumentación de lege ferenda, lo que la dogmática hace es argumentar de sentencia ferenda. Es decir, la dogmática no se reduce a constatar y reiterar las

\footnotetext{
${ }^{3}$ Leviathan, Capítulo XXVI.

${ }^{4}$ Alexy caracteriza a la dogmática jurídica como una "disciplina multidimensional", y distingue tres dimensiones básicas: (a) la dimensión descriptivo-empiríca (descripción de Derechovigente), (b) la dimensión lógico-analítica (penetración conceptual-sistemática del Derecho vigente), y (c) la dimensión normativo-práctica (elaboración de propuestas de solución de casos jurídicos problemáticos) (op. cit., nota 2, sección 2.4.1).
} 
disposiciones jurídicas positivas, ni tampoco realiza la crítica de política jurídica al derecho positivo con vistas a justificar la necesidad y el contenido de su reforma, sino que se esfuerza principalmente por justificar algunos enunciados normativos y en base a ellos recomienda al juez la mejor solución posible conforme al derecho vigente ${ }^{5}$.

6. Las aserciones más relevantes de la dogmática son las que tienen una orientación práctica, es decir, las que evidencian un "valor normativo". Este hecho las hace por supuesto sospechosas de "acientificidad", si se asume que el carácter científico de un enunciado exige neutralidad valorativa. Esto es lo que diferencia este tipo de los enunciados de la dogmática jurídica de aquello designado por Kelsen como "proposiciones-de-Derecho", o también, "enunciados jurídicos" ("Rechtssätze"), y que a su juicio constituyen el único tipo de enunciados metodológicamente legítimos de la ciencia del Derecho referida a un ordenamiento jurídico particular ${ }^{6}$.

Habria pues que decir que allí donde termina la capacidad explicativa de la ciencia del Derecho entendida al modo de Kelsen, alli comienza la labor más característica de la dogmática jurídica cultivada según la tradición del derecho continental. Si esa labor es "cientifica" o no, resulta una cuestión de segundo orden, a menos, claro está, que se considere que sólo es racional la argumentación científica. Pero no parece que esta aseveración tan estricta sea hoy en día defendible como lo fue en el Círculo de Viena.

7. En relación con la interpretación de los textos autoritativos, para clarificar este tipo de argumentación con valor normativo de la dogmática se puede recurrir a una distinción convencional, como es la que se hace entre una "disposición" y una

\footnotetext{
${ }^{5}$ En palabras de Luhmann: "En el plano de lo que se dispone sobre lo que es juridicamente posible no se puede distinguir con pleno sentido entre argumentos de lege lata y lege ferenda" (op. cit., pág 35). La tesis de Luhmann implica además consecuencias para la vinculación de la dogmática a la reforma legislativa.

${ }^{6}$ Hans Kelsen, Teoria Pura del Derecho, 2a. ed. (1960), Editorial Porrúa-Buenos Aires, Universidad Nacional Autónoma de México, Ciudad de México, 1991, capítulo III, sección 16. Para un agudo comentario sobre la teoría de los enunciados jurídicos de Kelsen, H.L.A. Hart, Kelsen Visited, en del mismo, "Essays in Jurisprudence and Philosophy", Oxford, 1993, págs. 286 y Ss..
} 
"norma", entendiendo la relación entre ambas de un modo análogo de la relación que existe entre un "enunciado" y su "significado"7 . Así, el derecho positivado se presenta como un repertorio de disposiciones, cuyo significado exige o puede exigir una determinación reflexiva para que ellas puedan cumplir su función de normas, en tanto premisas justificatorias de una decisión susceptible de ser impuesta coercitivamente. En la medida en que ella se relaciona con la interpretación del derecho positivado, se puede decir que la dogmática tiene por finalidad precisa la formulación de normas a partir de disposiciones ${ }^{8}$.

La transformación de la disposición en norma, es decir, la justificación externa depremisas normativas que apela-al menos parcialmente-a criterios procedimentales de validez, es una tarea argumentativa cuya comprensión constituye objeto de intrincadas polémicas. Como es evidente, cuál sea el rol que cabe desempeñar a la dogmática en esta tarea depende en gran medida de cómo se entienda la tarea en cuestión. Esta es una pregunta para la teoría de argumentación jurídica, la cual debe abarcar no sólo la argumentación jurídico-dogmática, sino muy especialmente la argumentación jurídico-jurisdiccional. No obstante, puede señalarse al menos aquello que la dogmática tiene en común con las demás formas institucionales de argumentación jurídica, y lo que parece tener como propio y exclusivo.

8. Tal como cualquiera otra forma de argumentaciónjurídica, la dogmática debe reconocer un límite o cierre en el proceso de justificación externa de las premisas normativas. En el contexto de justificación de sus argumentos, el discurso dogmático no se encuentra abierto a la crítica de modo indefinido, sino que sólo admite cierto repertorio de estándares de evaluación, todos sometidos a los criterios últimos de reconocimiento del derecho vigente.

La tensión existente entre la pretensión de rectitud del Derecho y su función social de descarga de la argumentación práctica es la tensión esencial de la argumentación jurídica. La dogmática jurídica participa de esa tensión precisamente en la medida en que constituye un modo de argumentación jurídica.

\footnotetext{
${ }^{7}$ Para esta distinción, y sus dos modalidades básicas de planteamiento, Jerzy Wróblewsky, Constitución y Teoría General de la Interpretación Juridica, Madrid, Civitas, 1985.

${ }^{8}$ Para un tratamiento detallado de metodología de la interpretación de la ley dogmática jurídica, Aulis Aarnio, Lo Racional como Razonable, Centro de Estudios Constitucionales, Madrid, 1991, págs. 91 y ss..
} 
9. A diferencia de la argumentación jurisprudencial o jurisdiccional, la dogmática intenta responder a la cuestión sobre la mejor solución posible sin constreñimientos ni urgencias prácticas institucionalmente reforzadas. El principio dela inexcusabilidad no vale en el discurso dogmático. La dogmática puede por ello tomar distancia frente al problema, así como frente al horizonte de soluciones disponibles, y postular de modo puramente conjetural una "tentativa de solución", o incluso admitir no haber aún elaborado una respuesta precisa para ciertas constelaciones de casos.

La ausencia de constreñimiento práctico de la dogmática queda compensada con la mayor extensión de su responsabilidad argumentativa. Para enjuiciar la aceptabilidad de una conjetura dogmática son pertinentes exigencias que serian impertinentes como criterios de evaluación de una decisión jurisdiccional en su contexto práctico inmediato. Es insensato esperar de un tribunal la demostración de la racionalidad de su decisión mediante un ejercicio complejo de modus tollens en contra de su ratio decidendi, del cual ésta sale sin embargo victoriosa. En cambio, sin un ejercicio semejante, es decir, sin una anticipación de intentos de refutación de la tesis defendida, y su respuesta anticipada, no hay buena dogmática jurídica. Es por esta razón que el caso imaginario tiene relevancia metodológica de primer orden en la dogmática, por más que su uso irrite hasta la exasperación al práctico.

10. Las constribuciones específicas de dogmática jurídica a la práctica racional de la administración de justicia en un sistema jurídico consisten: (a) en la generalización de los enunciados que forman parte del horizonte de referencia, y (b) en su integración en un sistema de enunciados. La generalización y la integración sistemática contribuyen a la racionalidad de la administración de justicia en la medida en que permiten reducir el margen de arbitrariedad de los órganos encargados de aplicación del Derecho, garantizando que los casos iguales reciban una misma decisión (generalización) y eliminado la imprevisibilidad de las decisiones por la vía de excluir las contradicciones de sus premisas justificatorias (integración sistemática).

En ningún aspecto se revela más claramente esta característica específica de la dogmática que en el tratamiento que ella hace de la jurisprudencia. Por su propia condición institucional, la jurisprudencia -ya sea bajo la regla del stare decisis o nono puede producir más que casuística. La dogmática, en cambio, compara y agrupa 
casos, y de ese modo construye constelaciones de casos, identificando el común denominador fáctico que es prioritario para el análisis jurídico por su relación con el principio de solución normativa. Al detectarse de este modo relaciones lógicas de subordinación, por ejemplo, se reduce el riesgo de arbitrariedad que implica la casuística por su aceptación indiscriminada de las posibilidades de diversificación de los criterios de solución.

11. Que en la realización de su cometido argumental específico la dogmática se valga de conceptos, y que ponga especial cuidado en su definición precia y en su correcto uso, se entiende por sí solo. Mal podría cumplirse el postulado de la coherencia del discurso dogmático si éste empleara sin justificarlo un mismo término con diversos significados, o si el significado de los términos empleados permaneciera en toda su extensión en la penumbra.

La dogmática procura formular, sin embargo, tan poco un sistema de conceptos, como puede decirse del derecho mismo que lo sea. Los conceptos dogmáticamente relevantes son siempre abreviaturas de complejos de enunciados ${ }^{9}$. El trabajo dogmático consiste, por cierto, en facilitar y asegurar la aplicación de los complejos de enunciados a través de la formulación de conceptos, pero también -principalmente- en someter a prueba los enunciados implicados por un concepto, y así revisar los conceptos. El "cielo de los conceptos" de Ihering es el paraíso de una dogmática a medias, que no sólo es mezquina en la admisión de posibles criterios de evaluación de la mejor solución jurídica posible, sino que además sustrae sus propias elaboraciones en una medida innecesaria al control de la argumentación crítica. El límite de las posibilidades argumentativas críticas de la dogmática, en tanto reconstrucción racional del derecho positivado, sólo está dado por el máximo sentido literal posible de las disposiciones jurídicas que sea compatible con el sentido de las disposiciones jurídicas de rango jerárquico superior.

12. La dogmática jurídica evidencia además pretensiones de racionalidad peculiares, orientadas a la "fundamentación" del derecho positivo. Se entiende que estas pretensiones despierten suspicacias. En la medida en que por fundamentación se

${ }^{9} \mathrm{Al}$ respecto, Popper, Epistemologia sin Sujeto Cognoscente, en del mismo, "Conocimiento Objetivo" (1972), Madrid, 1982, págs. 106 y ss.. 
entienda la legitimación del derecho positivo, la pretensión fundamentadora pone en entredicho la vinculación del discurso dogmático al derecho positivo del modo que es propio de la argumentación jurídica (ver punto 8). Para no romper su compromiso con el uso de criterios procedimentales de validez, es decir, para no abrirse indefinidamente a la cuestión práctica de la justificación externa de las premisas normativas, la dogmática se vale de la estrategia de explicitar y hacer fructíferos en términos práctico-jurídicos los presupuestos de racionalidad implícitos o inmanentes del derecho positivo. Estos presupuestos son principalmente de tres clases o tipos:

a. Presupuestos metajurídicos indisponibles, que corresponden a las condiciones del mundo, del hombre y de la interacción mediada por el lenguaje en que tiene lugar el Derecho como sistema normativo. La apelación de premisas metafisicas, antropológicas o de la teoría de las normas para encontrar una base de análisis de las cuestiones más generales de la dogmática jurídica tiene sentido en la medida en que se trata de presupuestos no disponibles por el legislador. Su déficit como premisas dogmáticas se encuentra sin embargo en su carácter eminentemente conjetural y revisable desde un punto de vista teórico. La dogmática jurídica que ingenuamente apela a estas premisas como una manera de liberarse del carácter contingente de la voluntad legislativa, desconoce el carácter contingente de la voluntad legislativa, desconoce el carácter culturalmente provisional de las teorías metafísicas o de las ciencias sociales.

b. Presupuestos legitimatorios generales, que corresponden de los principios de la teoría de la Justicia que se postule como núcleo de significado de la Constitución. La pertinencia dogmática de estos presupuestos viene asegurada por el principio de la supremacía jerárquica de la Constitución, y su fertilidad, por su condición de principios jurídicos, esto es, de mandatos de optimización ${ }^{10}$. El involucramiento de los principios constitucionales es sin embargo uno de los desafios metodológicos más arduos que debe enfrentar hoy en día la dogmática, porque hace explícitos sus presupuestos políticos más generales. La apelación a principios constitucionales exige una teoría de la función política del Derecho, como complemento institucional de la teoría de la justicia que sirve de base a la interpretación de la Constitución. Por

${ }^{10} \mathrm{Al}$ respecto, Manucl Atienza, Juan Ruiz Manero, Las Piezas del Derecho, Barcelona, 1996. págs. 6 y ss.. 
ello, la vieja disputa entre la comprensión liberal de la Constitución como marco legitimatorio limitante de las potestades estatales y su comprensión antiliberal como marco legitimatorio programático de las potestades estatales se renueva al interior de la discusión dogmática.

c. Presupuestos genéticos, que corresponden al horizonte de referencia dado por el Derecho comparado que sirvió de base histórica a la fijación del texto legal. La relevancia de los antecedentes históricos de la legislación aumenta exponencialmente tratándose de una codificación dependiente, como lo fue $-\mathrm{y}$ no puede dejar de serlo- la codificación chilena. En la medida en que la regulación fijada en un texto autoritativo responde a una tradición argumentativa precedente, el contexto de esta tradición - el proceso argumentativo históricamente acaecido y racionalmente reconstruible- es el trasfondo que hace inteligible de la legislación como respuesta racional -y no puro voluntarismo- a una cuestión de relevancia práctica. El examen de los presupuestos genéticos de la codificación permite reconciliar la pretensión de racionalidad del Derecho con su condición histórica.

13. De lo anterior se desprende que no todo el material legislativo es igualmente apto para su tratamiento dogmático. La cuestión de la aptitud dogmática del material jurídico no es, naturalmente, una cuestión susceptible de determinación mediante un esquema de todo-o-nada, sino que es algo gradual. Es apto en grado máximo el material jurídico que a la vez admite ser considerado como moralmente evidente o bien como conceptualmente fundado, es decir, el texto cuyo contenido corresponde a una tradición argumentativa, ya sea práctico-general o bien técnicojurídica. La distinción escolástica entre la maldad como razón de la prohibición y la prohibición como razón de la maldad mantiene así al menos su relevancia pragmática para el reconocimiento de las posibilidades del desarrollo argumental de la materia de la prohibición.

14. Las notas anteriores han seguido un hilo que va desde las consideraciones lógicas o semánticas -la dogmática como un sistema de enunciados- hacia las consideraciones históricas o pragmáticas-la dogmática como sistema de acciones. Al igual que la ciencia en general, la dogmática jurídica sólo es plenamente comprensible como una actividad argumentativa institucionalizada. La existencia 
de la dogmática jurídica supone un elevado grado de diferenciación de las profesiones jurídicas dentro del sistema, que permita el reconocimiento entre juristas, por una parte, y jueces y abogados, por la otra parte, como personas que desempeñan roles argumentativos muy diversos en el sistema. La diferenciación del rol de jurista supone a su vez la existencia institucional de una comunidad argumentativa, que se distingue también institucionalmente del sistema jurisdiccional. Es fácil comprender que la interacción entre una y otra profesiones (o entre uno y otro subsistemas del sistema jurídico) no se encuentra exenta de tensiones o incomprensiones mutuas. No obstante, la necesidad de dicha interacción se hace evidente una vez que los juristas reconocen y responden a la orientación práctica de la dogmática, y los jueces reconocen y responden al modo racional-sistemático de hacer valer la pretensión de rectitud del Derecho.

15. También al nivel de la legislación tiene un rol que cumplir la dogmática jurídica, en la medida en que se mantenga políticamente vigente el imperativo de racionalidad sistemática en la creación del Derecho, característico de la modernidad. En este sentido, bien puede decirse que la dogmática no es más que otro modo de realización del ideal de la codificación.

En la concentración de la aspiración de racionalidad en la dogmática, en vez de en la legislación, se encuentra sin embargo un rasgo distintivo de la aproximación crítica al ideal de racionalidad, por oposición a su asunción ingenua, también característica de la modernidad. La asunción de la falibilidad del conocimiento y de su carácter inevitablemente conjetural marca la diferencia entre el impulso argumental de la dogmática jurídica del Siglo XX y el de la escuela de la exégesis francesa del Siglo XIX. La dogmática jurídica comparte de ideal de racionalidad sistemática de la codificación sin asumir que la legislación puede realizar ese ideal de modo satisfactorio y definitivo.

Negar a la clase de los juristas la capacidad de llevar adelante dicho ideal en el nivel argumentativo de la dogmática es - parafraseando otro pasaje de Hegel en el lugar citado al inicio de estas observaciones-, el mayor insulto de que se los puede hacer objeto. 